\title{
Introduction to Energy Efficiency Through Bioclimatic Design: Case Studies, Quantitative Verifications and Regulatory Management
}

\author{
Maria Jose Panvini, Romina Saldi \\ Architecture Planning and Design Faculty, National University of Rosario, Rosario, Argentine
}

Email address:

mjpanvini@yahoo.com.ar (M. J. Panvini), rominasaldi@hotmail.com (R. Saldi)

\section{To cite this article:}

Maria Jose Panvini, Romina Saldi. Introduction to Energy Efficiency Through Bioclimatic Design: Case Studies, Quantitative Verifications and Regulatory Management. American Journal of Modern Energy. Vol. 7, No. 5, 2021, pp. 82-91. doi: 10.11648/j.ajme.20210705.12

Received: August 4, 2021; Accepted: August 17, 2021; Published: November 23, 2021

\begin{abstract}
Optional Curriculum Subject "Introduction to energy efficiency for housing" seeks to internalize in students the need to conceive project idea through an integral thought that contemplates design guidelines with passive architecture criteria and link theoretical topics taught in different subjects of Architecture career in relation to energy efficiency to be applied in the project practice in a concrete way. It is essential to introduce the importance of using natural and climatic resources responsibly, these being crucial for people, society and environment. Investigating a series of project resources allows mitigating and reducing environmental impact generated by a building as a contribution to climate change. Digital tools and calculation methods will allow verification of the correct location of construction on site, study orientations, solar radiation, prevailing winds and efficient envelope design preferably materialized with materials from the region. The knowledge of site and climate and correct control and management of energy and materials, are aspects that make the project sustainable, therefore, they are taken into account in the teaching of the subject as a starting point in the student's task as a future professional of architecture. The proposed practical exercise must comply certain items that are partially and methodologically resolved as the theory is taught. We work on three types of single-family homes on ground floor implanted in a bioclimatic area of your choice. Students must analyze them according to climatic principles and strategies to determine which typology is best adapted according to the passive design criteria and recommendations for said area. This implies verifying dimensional and energy indicators and building thermal quality of buildings. Through modality of integration seminar that consists of a graphic and quantitative synthesis, debate and exchange of ideas and final reflections are carried out. The objectives indicated from the teaching-learning were successfully achieved, with the theoretical topics applied correctly. Use of digital tools, thermographic images and 3D modeling was evidenced.
\end{abstract}

Keywords: Passive Architecture, Comfort, Energy, Norms, Resilience

\section{Introduction}

"If architecture is to have relevance in the future, it will be necessary to change the architectural rules established during the last decades and try to understand how it can be projected with nature and not against it. Current buildings, like traditional ones, must take advantage of the natural energies of the sun and wind, incorporating them through their architectural design". Gerald Foley [1].

It can be said that a home is energy efficient when, through a passive bioclimatic design, energy consumption is reduced or minimized. This fact does not imply giving up the objective of achieving comfortable environments. Buildings are important consumers of energy and the ways in which they are designed, constructed, used, demolished and replaced form a substantial part of general logics of urban organization. For these reasons, optional subject to which practical exercise belongs aims to internalize in students awareness of bioenvironmental problem and the need to conceive project idea through an integral thought that contemplates design guidelines with criteria passive architecture. These will be related to energy efficiency to be later applied in project practice in a concrete and reliable way. 
In this context, a building must be considered as a "system" that, through design strategies, achieves thermal comfort avoiding use of artificial conditioning.

Chosen typology together with thermo-physical characteristics of construction elements of envelopes and properties of materials are aspects that students must know and apply in their passive design proposals to optimize thermal behavior in certain bioclimatic zones.

If a house is well designed, its energy losses will not be excessive, energy consumption will be comparatively low and polluting emissions that produce greenhouse effect gases will also be reduced, thus achieving reference objective.

\section{Method}

Optional Curriculum Space is made up of an interdisciplinary teaching team and has presence of more than seventy students. Presential course is approached and an integrative practical exercise is developed by groups of students of four members.

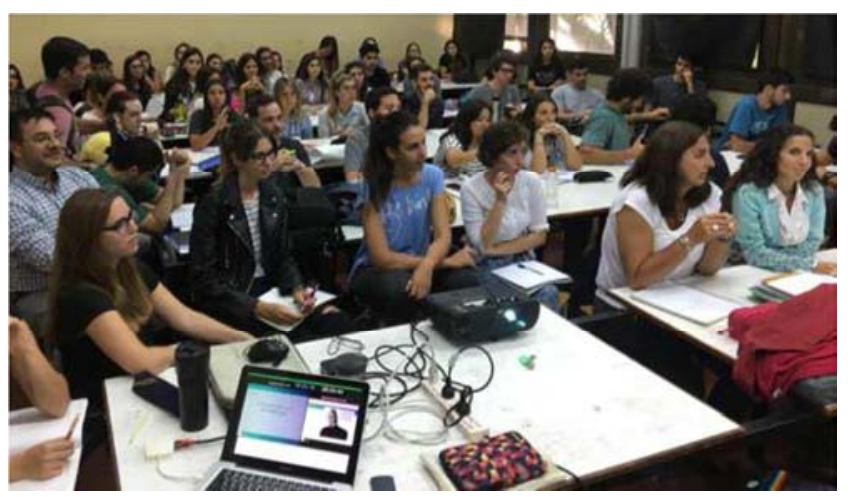

Figure 1. First class.
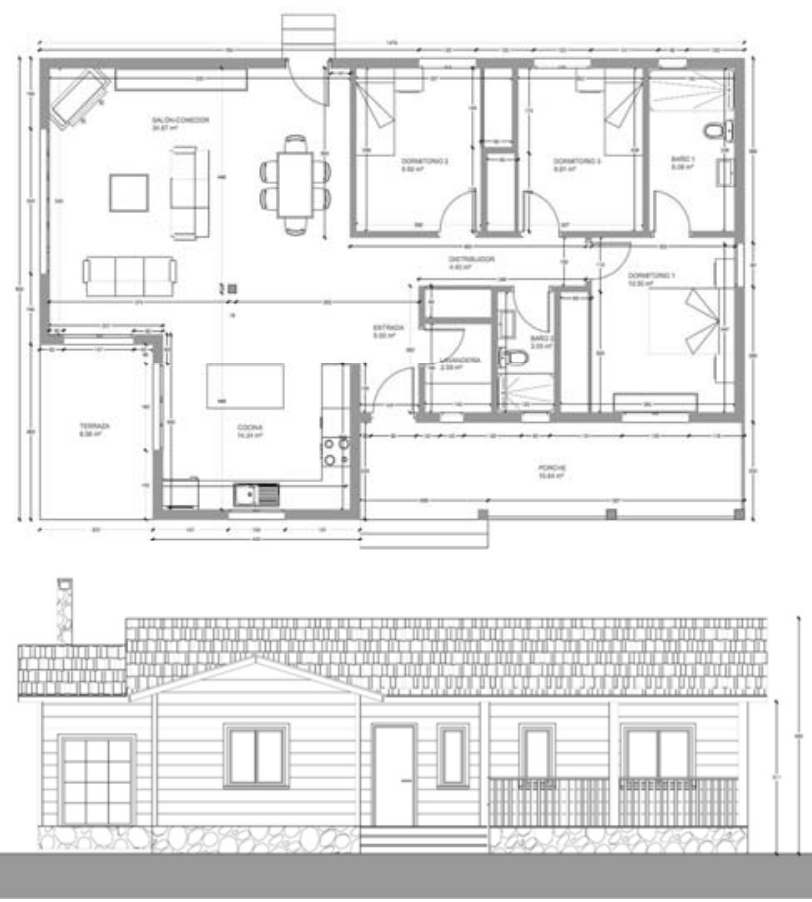

Figure 2. Compact typology.
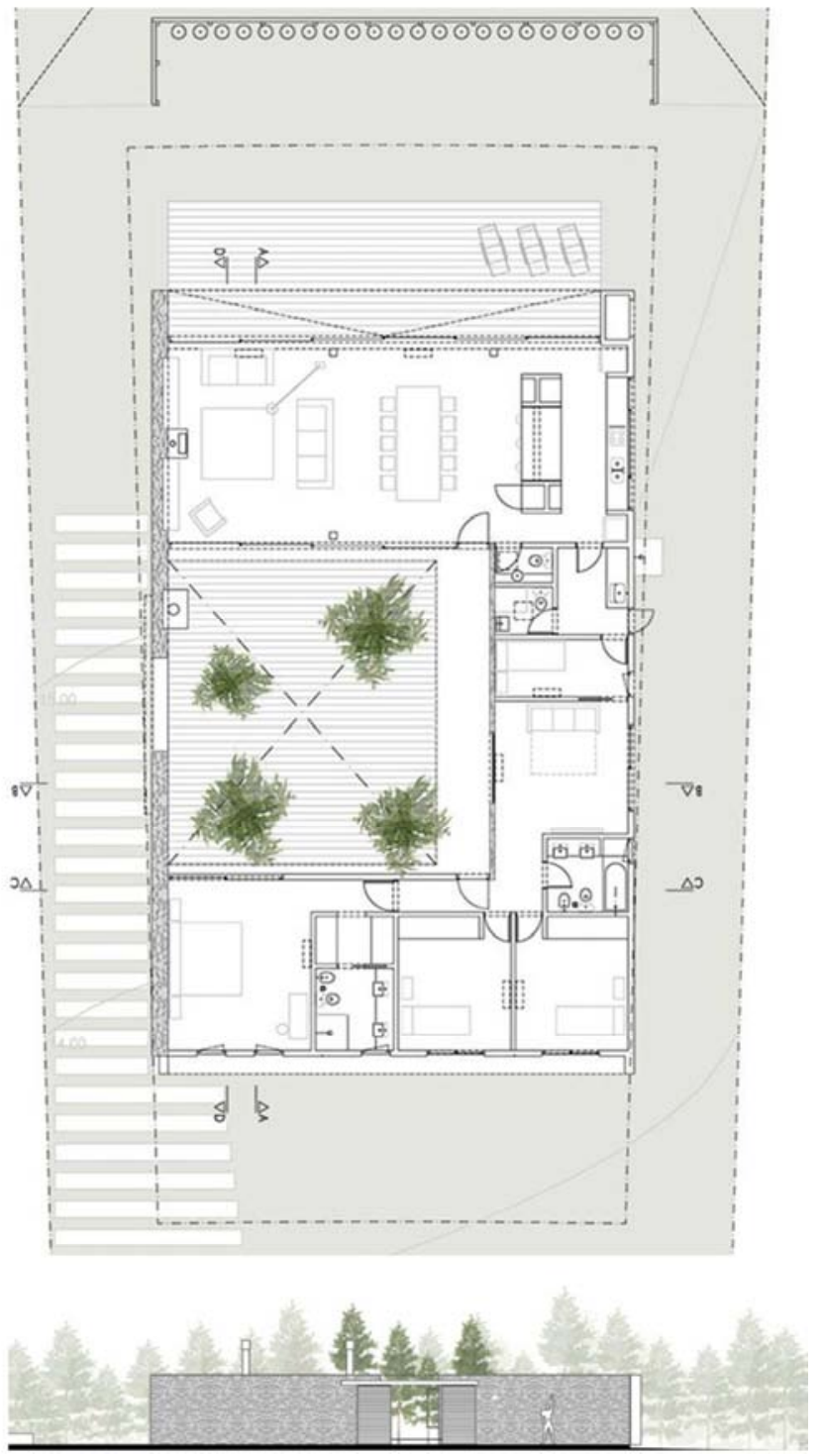

Figure 3. Compact typology with courtyard.

It is presented by teachers on first day of classes. Points that make it up are progressively taught as well as theoretical topics to be applied in it (Figure 1). Use of VLE (Virtual Learning Environments) is also incorporated through moodle platform available at faculty: http://moodle.fapyd.unr.edu.ar/course/view.php?id=164.

There, documentation of theoretical classes and a series of reference files are shared, provided by teachers and external advisers. Methodology of the practical exercise consists of study of three cases of different typologies of single-family houses. These are ground floor projects of compact type (Figure 2), another compact with courtyard (Figure 3) and one of open typology (Figure 4). 


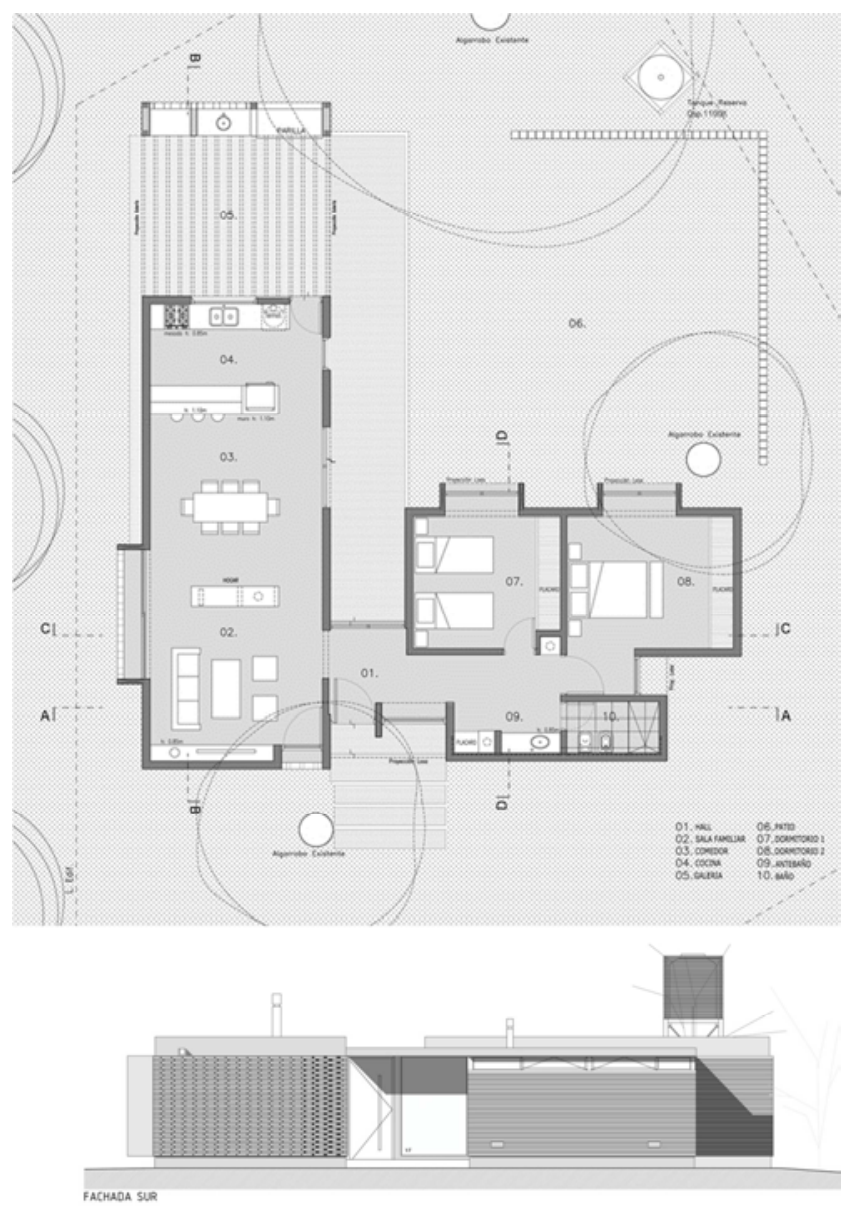

Figure 4. Open typology.

When starting home analysis process, it is essential to know environmental conditions of environment in which it will be located, taking into account both positive and negative aspects that climate offers. Students implants project in a field of choice located in a certain bioclimatic zone and analyzes three houses according to passive design criteria and recommendations for said zone.

Determining which typology is best suited involves verifying dimensional and energy indicators and building thermal quality, that is, energy losses depending on climate. This implies fulfillment of seven items that are partially and methodologically resolved as theoretical topics of the subject are taught.

During the course, partial checks and progress of the inquiries are generated (Figure 5).

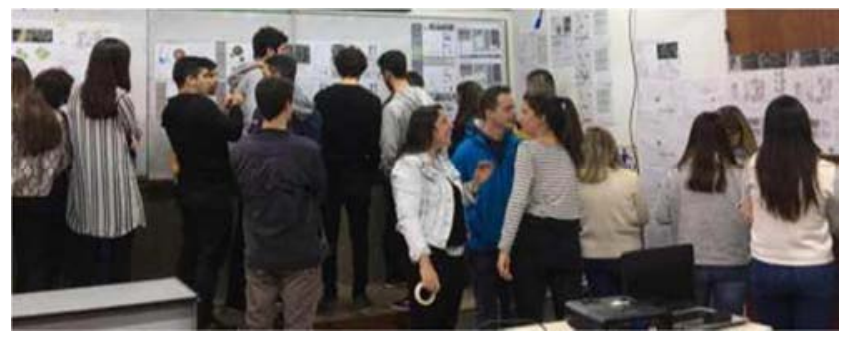

Figure 5. Parcial progress.

After analyzing and verifying three types of / or already known, justification in between, students chooses type that best suits bioclimatic zone adopted. Choice arises from verifications and conclusions obtained, deciding on type that least interventions and / or modifications require to suit region to be implemented, always bearing in mind that homes are pre-designed projects. This implies not projecting them from scratch but rather, from a critical analysis, suggesting possible recommendations and / or passive design strategies that make possible their adaptation in order to obtain better results to achieve an energy efficient housing.

Through integration seminary modality, which consists of a graphic and oral presentation, debate and exchange of ideas and final reflections are carried out. Based on results obtained, final proposals are exhibited for appreciation of educational community in gallery of samples of Architecture, Planning and Design Faculty of UNR. (Figure 6).
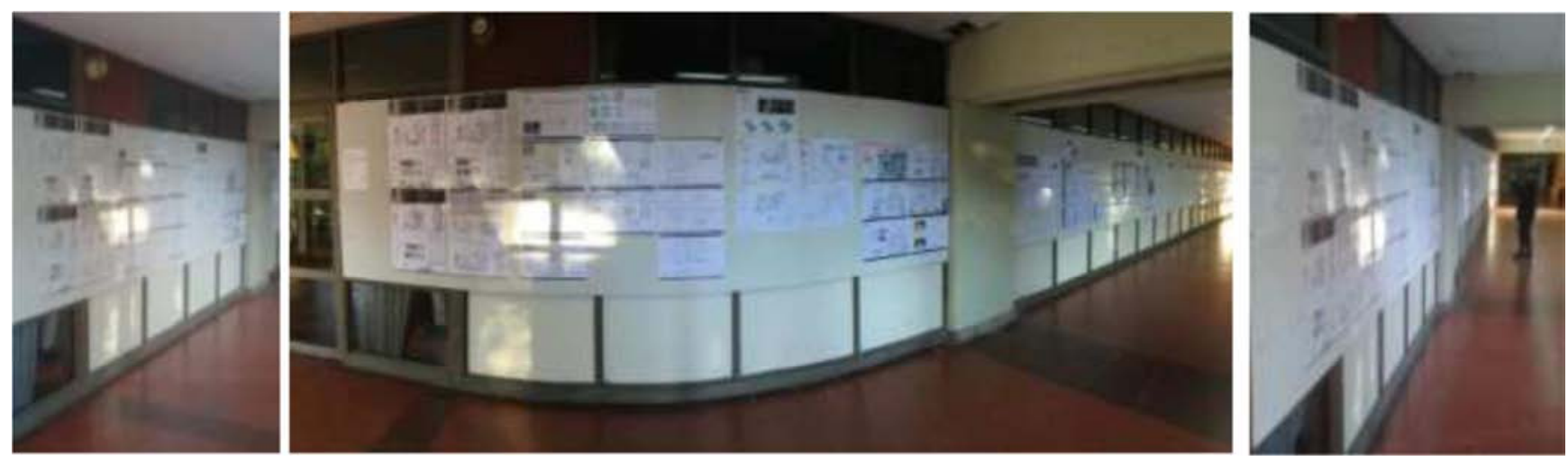

Figure 6. Gallery of samples of Faculty of Architecture, Planning and Design of UNR.

\section{Development}

Development of the integrative practical exercise consists of seven items to be fulfilled that are exemplified below:

\subsection{Analysis}

Analysis of geographic factors (latitudes, minimum temperatures, relative humidity, prevailing winds, rainfall, heating degree days) that determine climatic characteristics 
of different bioenvironmental zones [2] (Figure 7).
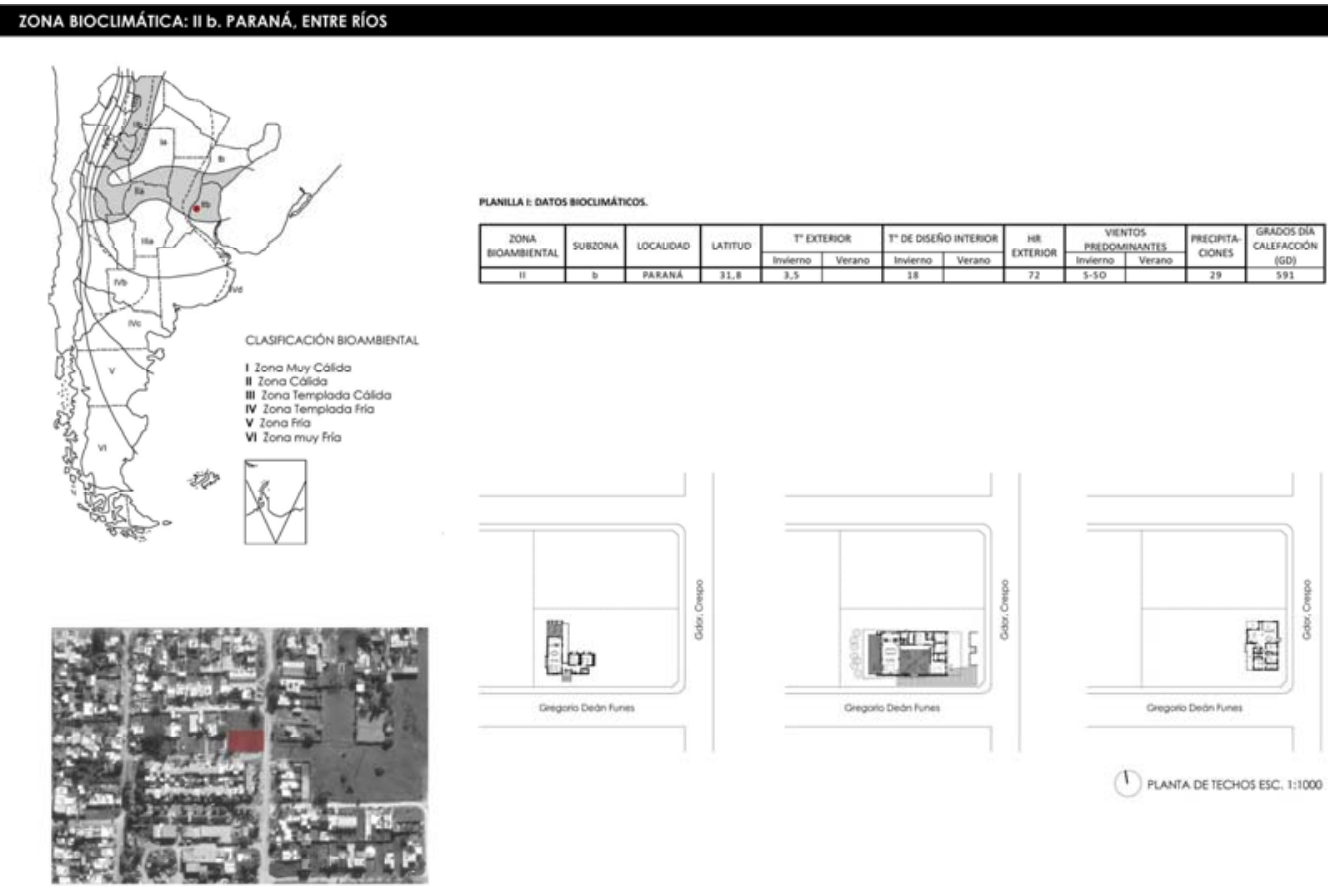

EFICIENCIA ENERGÉTICA PARA VIVIENDAS

Figure 7. Analysis of Geographic factors. Authors Gaggiano, Gaspar, González del Cerro, Fransolini.

\subsection{Study of Guidelines and General Principles for Bioclimatic Design (Figure 8)}

The following topics that are part of bases and principles of an adequate bioclimatic design will be analyzed: implantation of building on ground, natural ventilation, favorable orientations, minimum sunlight required, arrangement of interior spaces, size and orientation of windows, identification of solar protections, natural lighting.

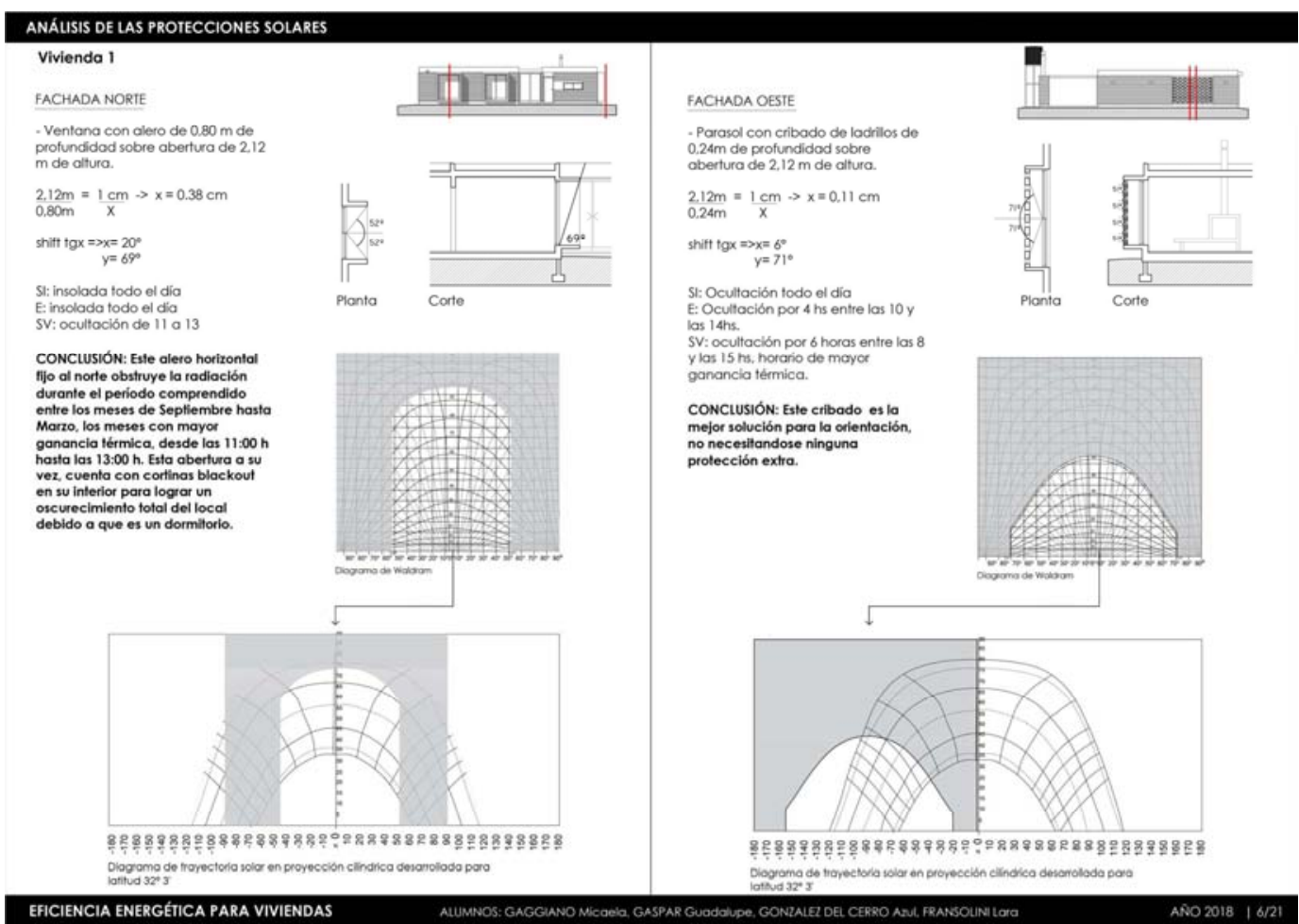




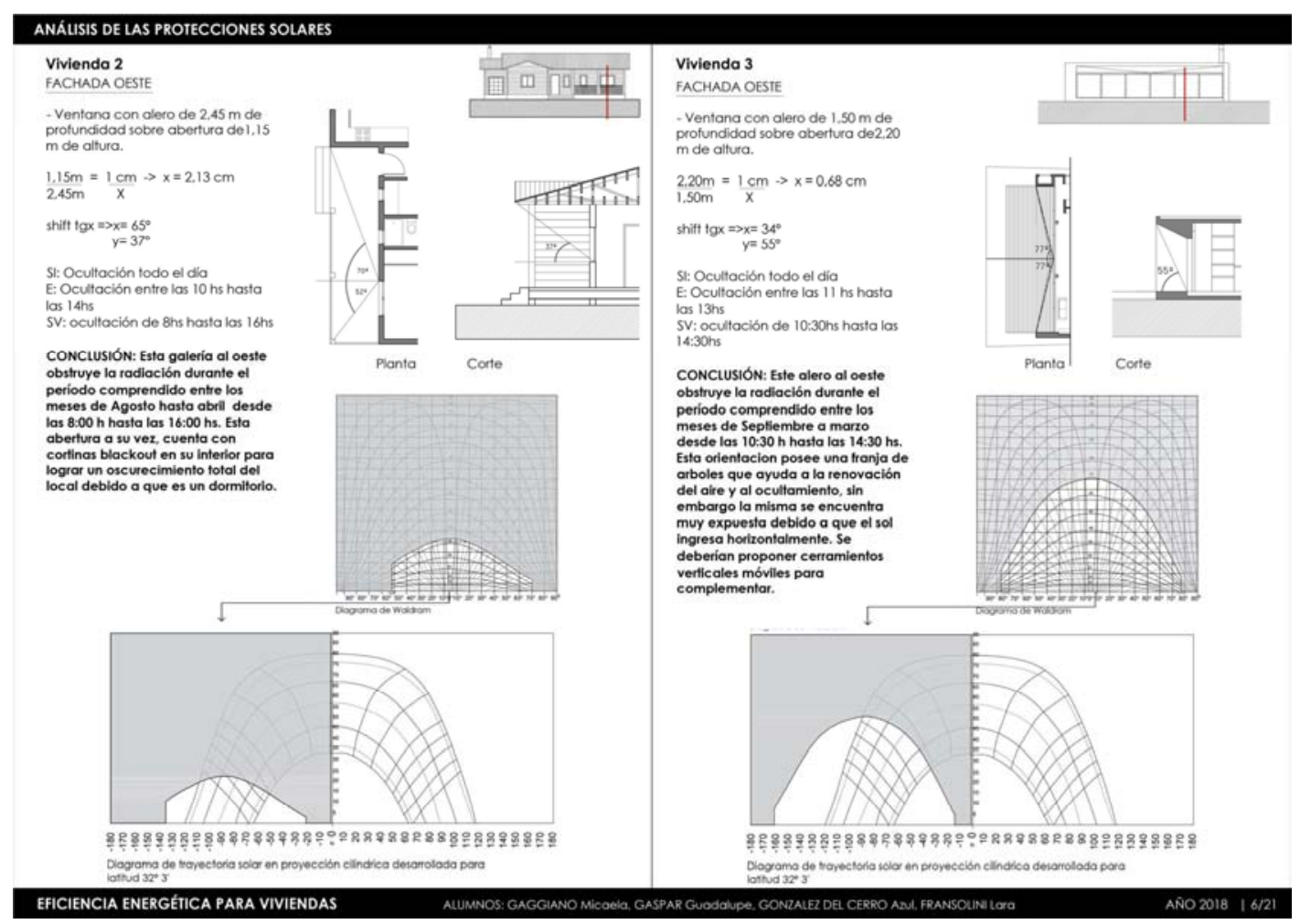

Figure 8. Study of general guidelines for bioclimatic design Authors Gaggiano, Gaspar, González del Cerro, Fransolini.

\subsection{Analyze Previous Points According to Tables Prepared by Teachers (Figures 9 and 10)}

Identify and or decide strategies adopted in each typology according to criteria and recommendations mentioned in tables provided by teaching team: Recommendations of passive design strategies [3], Effects of the climate of the different regions on the shape of the house [4], Criteria and recommendations of bioclimatic design for the arrangement of the complex [5] and Criteria and design recommendations bioclimatic for house ordering [6]. Strategies representation synthesis graphics suggested by teachers may be used.

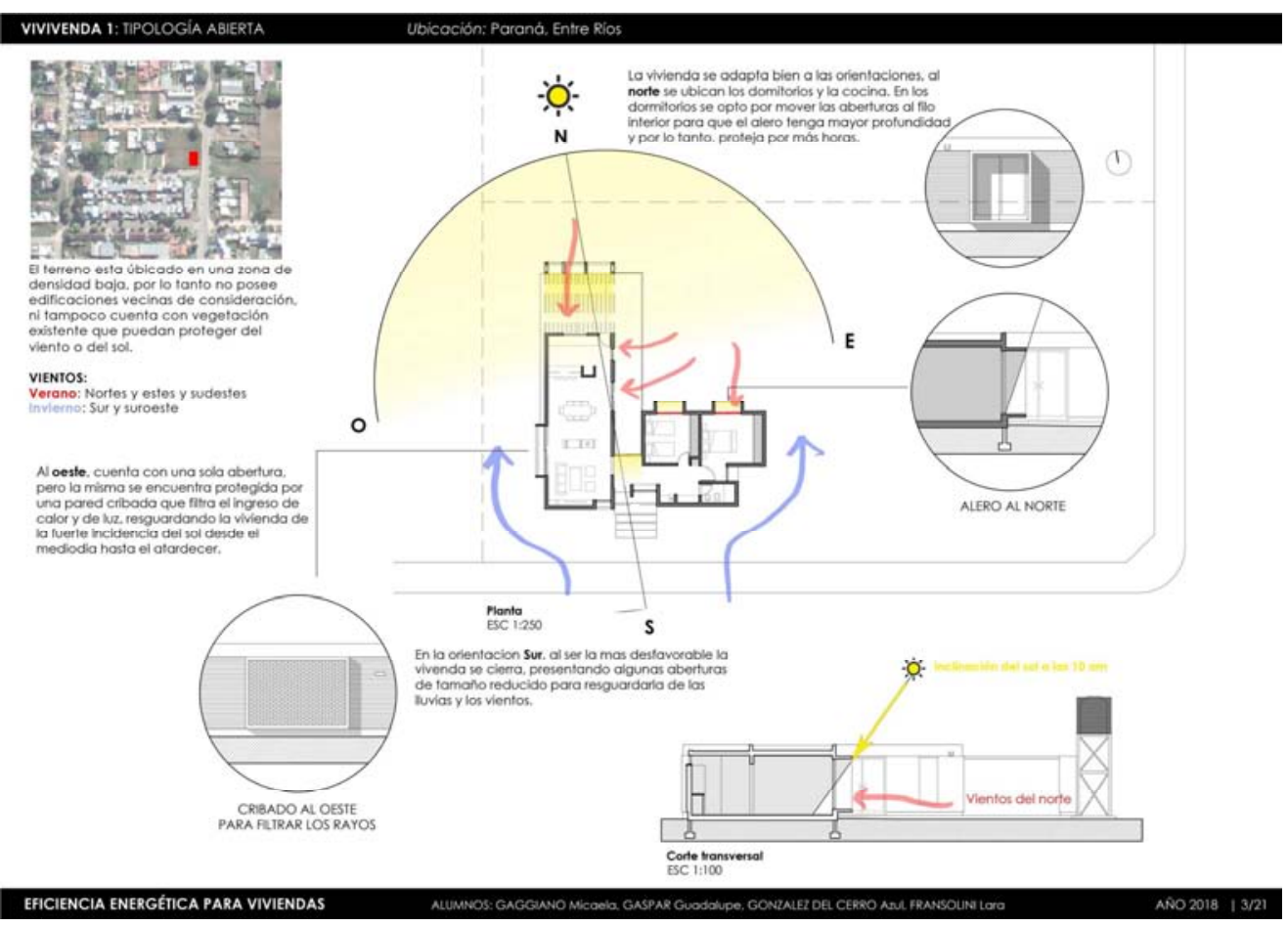




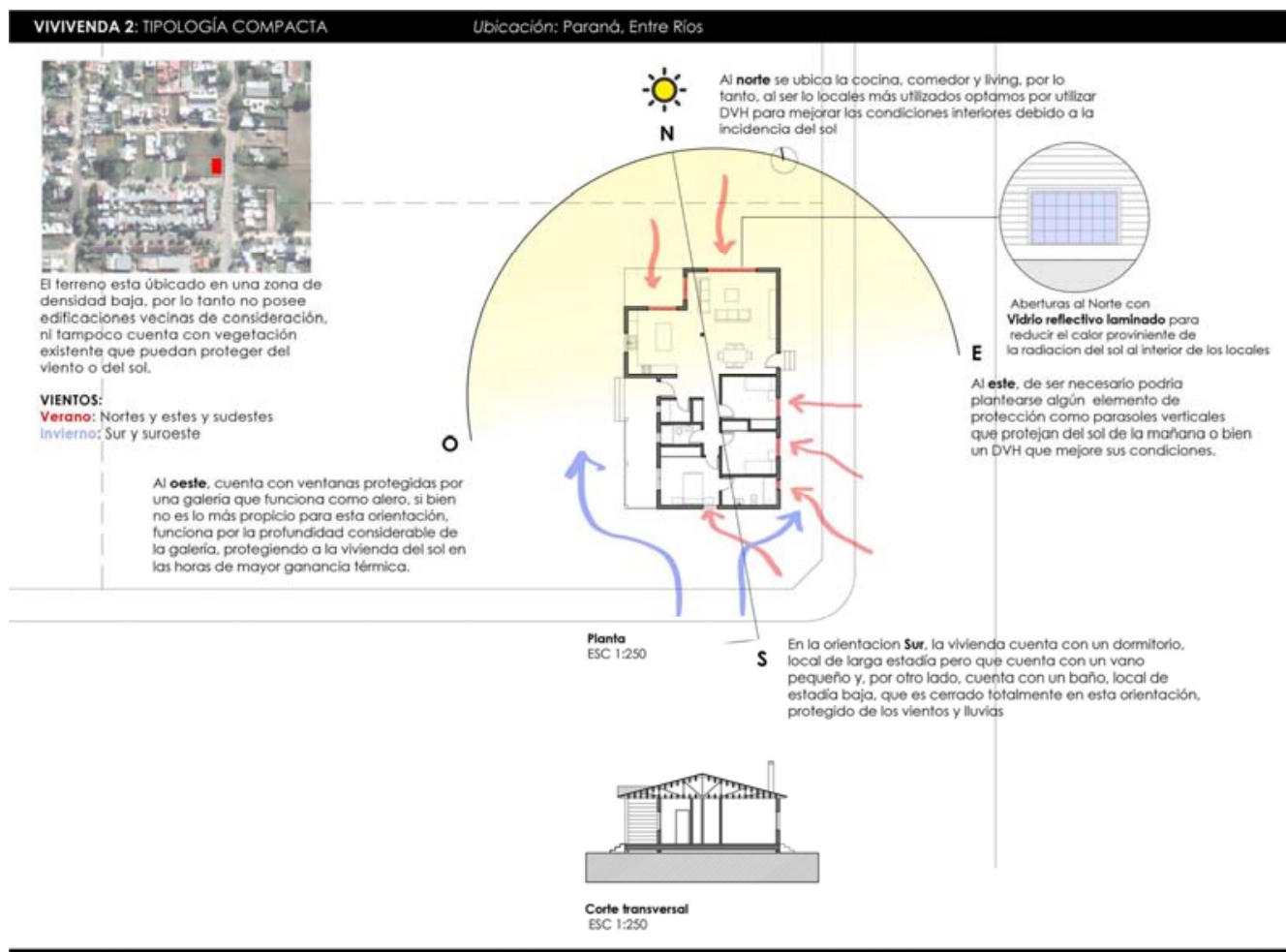

EFIIENCIA ENERGÉIICA PARA VIVIENDAS

Figure 9. Analyze previous points. Authors Gaggiano, Gaspar, González del Cerro, Fransolini.

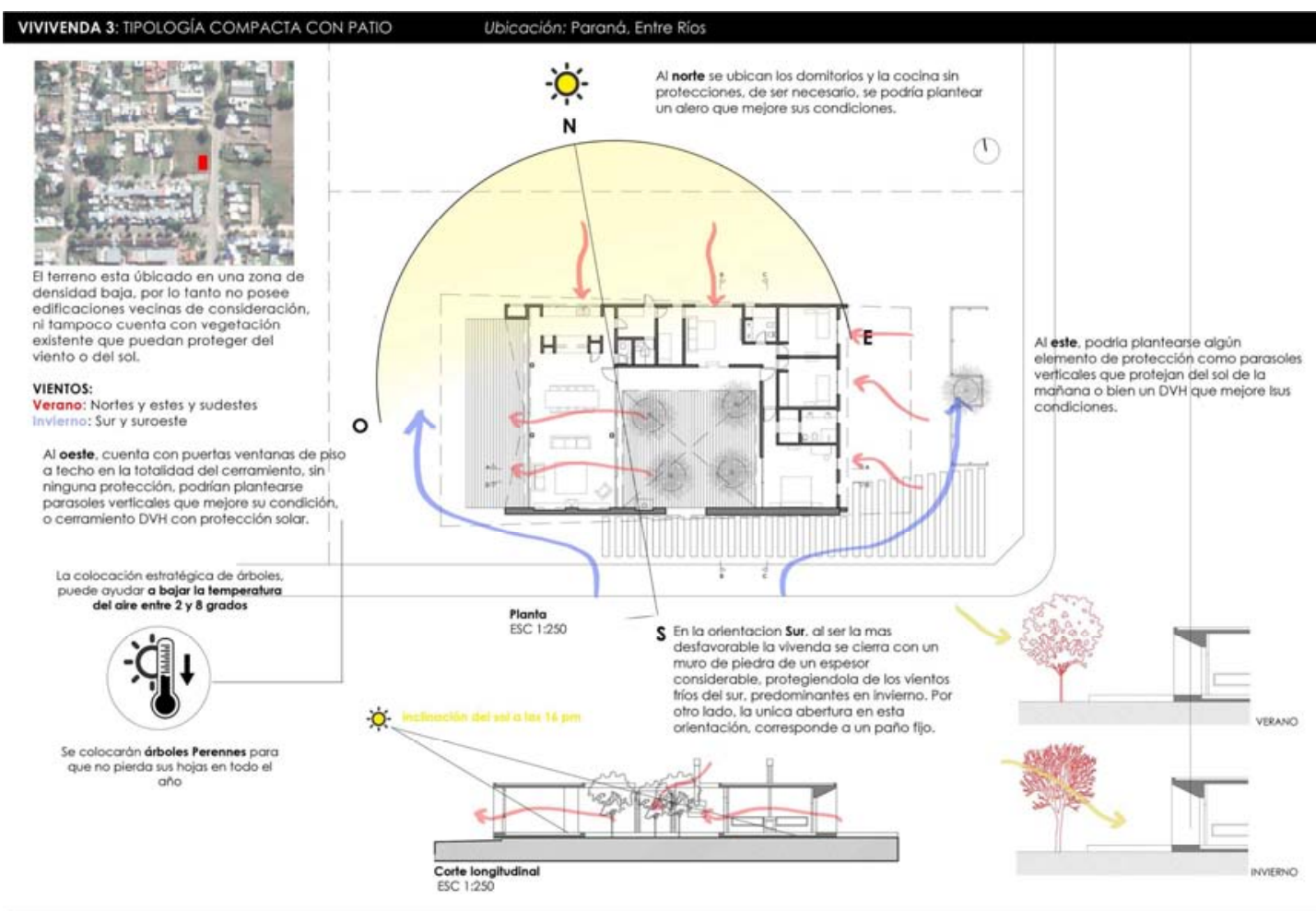

Figure 10. Authors Gaggiano, Gaspar, González del Cerro, Fransolini.

\subsection{Evaluation}

Evaluation of architectural form in relation to conservation of energy: dimensional indicators FFEA (Factor Floor Envelope 
Area): relationship between envelope surface with respect to floor surface) (Figure11).
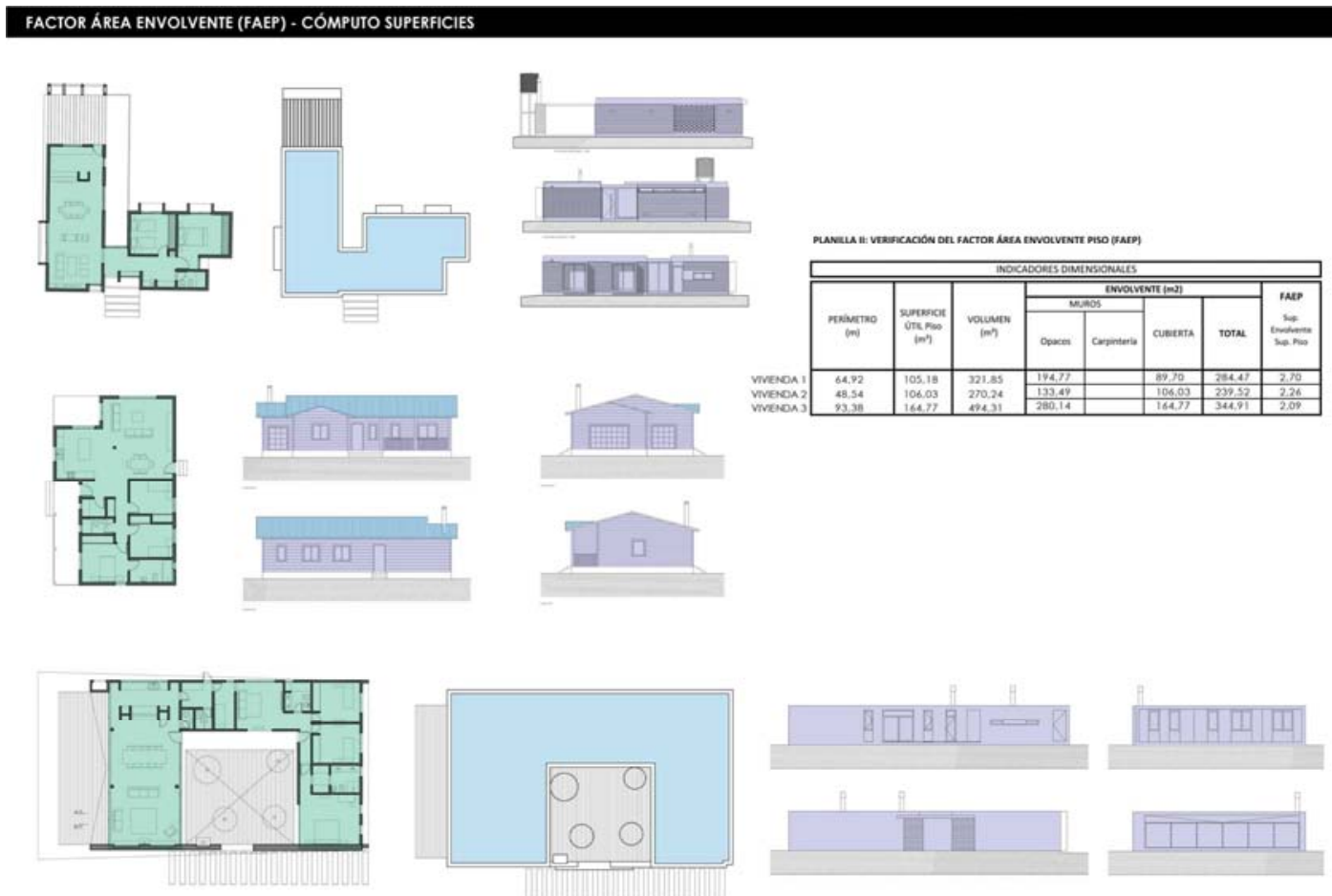

EFICIENCIA ENERGÉ́IICA PARA VIVIENDAS

Figure 11. Evaluation of architectural form. Authors Gaggiano, Gaspar, González del Cerro, Fransolini.

\subsection{Propose}

Propose solutions for vertical and horizontal envelopes for three typologiesn (Figure 12). Verification of energy behavior (thermal transmittance of horizontal and vertical opaque and glazed windows, surface and interstitial condensation and SEF (Solar Exposure Factor) [7-14].

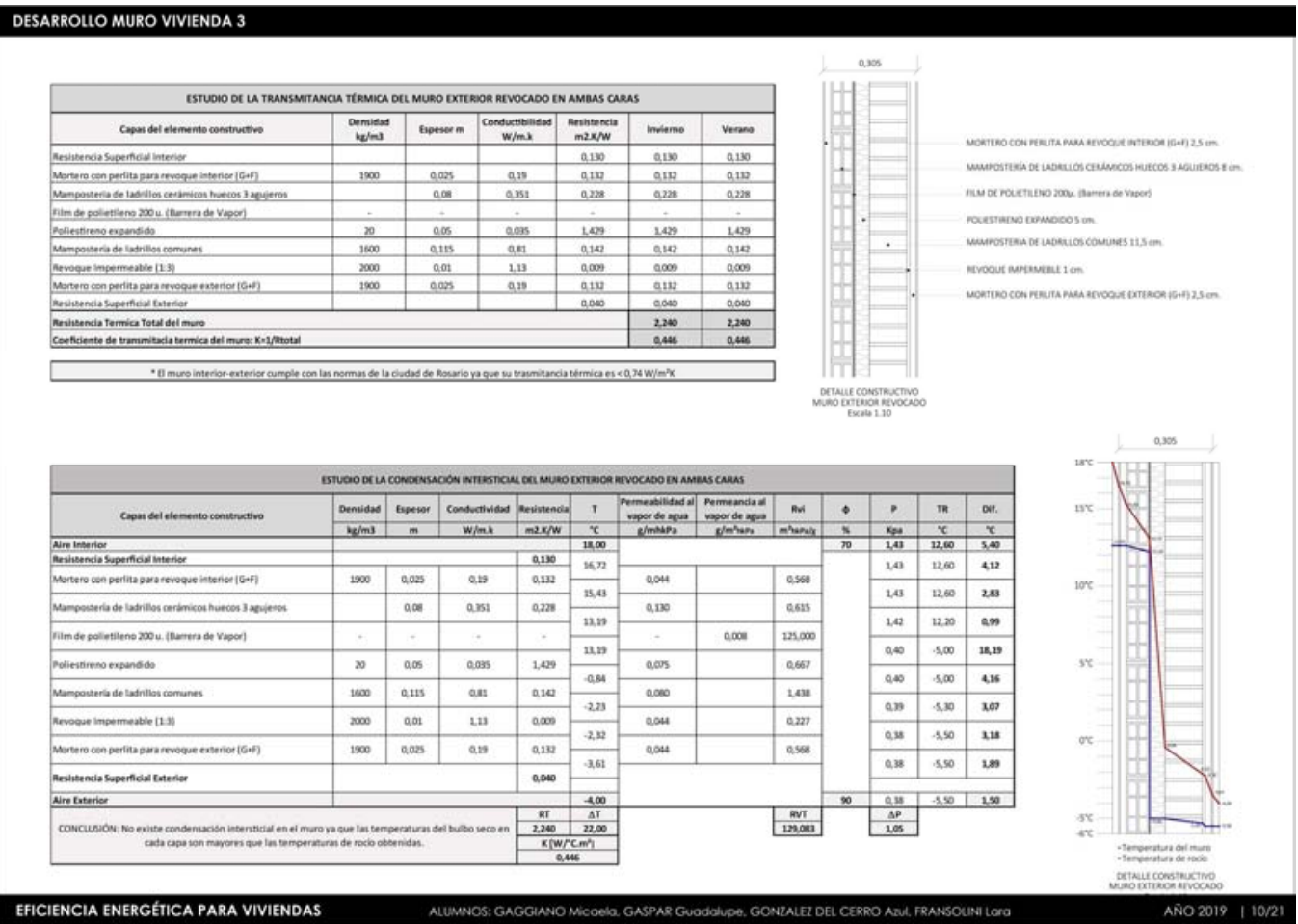



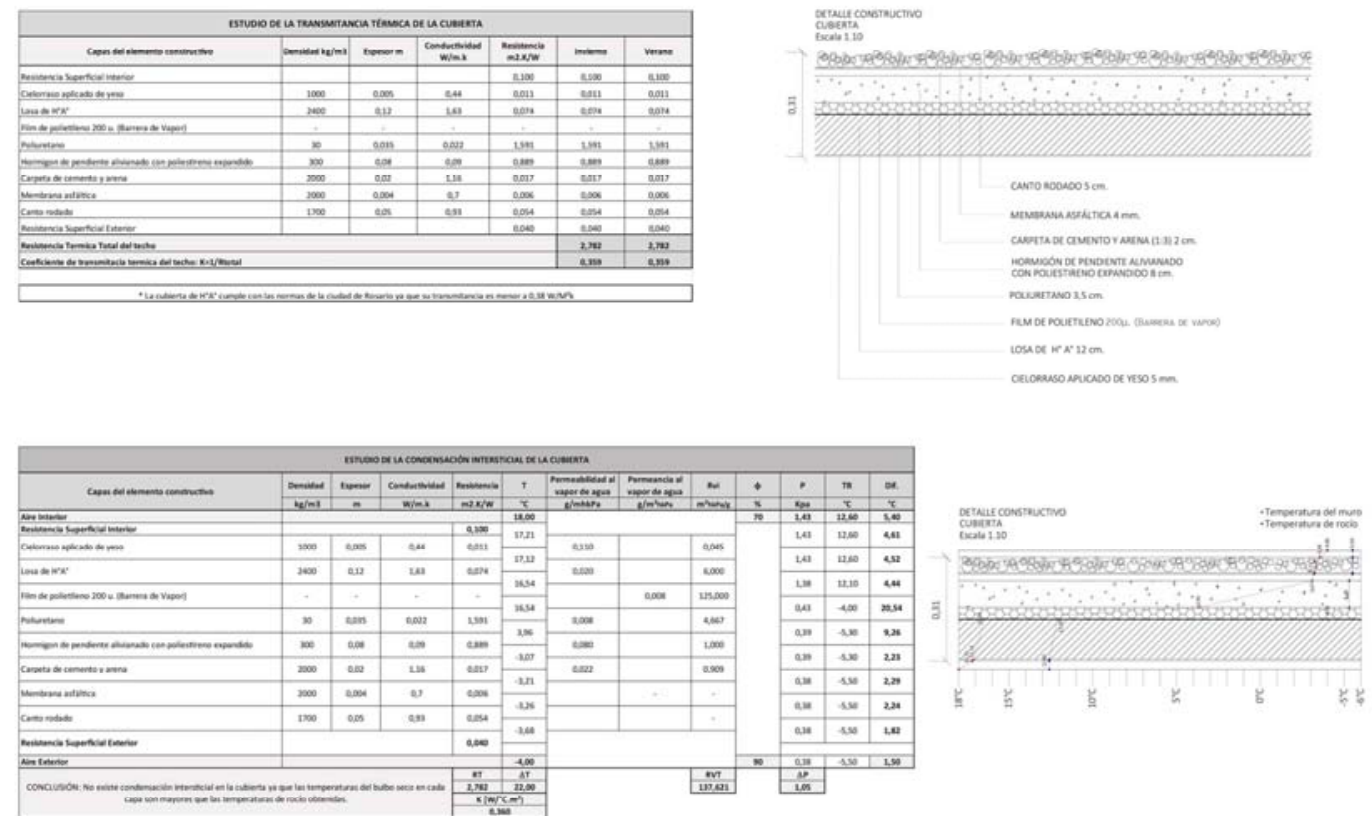

Figure 12. Verification of energy behavior. Authors Gaggiano, Gaspar, González del Cerro, Fransolini.

\subsection{Calculation of Global Volumetric Heat Loss (Coefficient G)}

Calculation and verification of Global Volumetric Loss $(\mathrm{G})$ IRAM 11604: 2001 [15]. Global coefficient of thermal losses $\mathrm{G}\left(\mathrm{W} / \mathrm{m}^{3}{ }^{\circ} \mathrm{C}\right)$, is defined as amount of thermal energy that a heated room loses per unit volume, per unit of time and for each degree of temperature difference in steady state.

Calculation value must not exceed maximum admissible value set in standard to comply with required energy savings.

\subsection{Determination of Annual Thermal Load (Kwh / Year)}

To carry out corresponding quantifications, students determines and verify them according to IRAM (Argentine Institute of Standardization and Certification) Standards [1115], and / or Rosario Municipal Ordinance 8757 [7] according to bioenvironmental zone [2]. Rosario City belongs to bioenvironmental zone III "a". It was the first city in Argentina to implement measures to reduce energy from thermal conditioning in both heating and cooling in construction.

Values should not exceed maximum admissible set in standards to comply with energy savings. Beyond results obtained, these values provide students with a numerical indicator of thermal efficiency of each project, becoming an auxiliary of interest in construction design process.

Determination of annual thermal load (Kwh / year), as a last step, allows to know how much primary energy is needed annually to keep house constantly at $18^{\circ}, 20^{\circ}$ or $22^{\circ} \mathrm{C}$ (depending on degree of heating days adopted), and thus be able to compare annual thermal loads of heated homes and know cost of energy necessary to maintain that comfort, making it possible to estimate energy savings derived from possible improvements on thermal characteristics that they imply.

\section{Conclusions}

We conclude as a teaching team of optional curricular space that objective pointed out from teaching - learning was successfully achieved by students. They were enthusiastic in the use of digital tools such as incorporation of thermographic images and 3D modeling (Figure 13).

Theoretical topics taught were applied correctly. Most of groups used natural resources as passive design strategies (Example: use of vegetation to reduce effect of prevailing breezes).

As a future contribution to what has already been produced, we find it interesting to incorporate into study and verification the application of IRAM 11900 (2010) [16] Standard for energy performance in homes. Aforementioned standard establishes a simplified methodology for calculating level of energy efficiency of envelopes of buildings that can be heated. It establishes eight levels of thermal efficiency following format of energy efficiency labels of household appliances. Level is determined by calculating weighted average temperature variation between interior surface of each component of envelope and interior design temperature $\left(20^{\circ} \mathrm{C}\right)$.

Its purpose is to have a rough idea of energy savings that can be achieved by improving quality of housing envelope if it is necessary. 

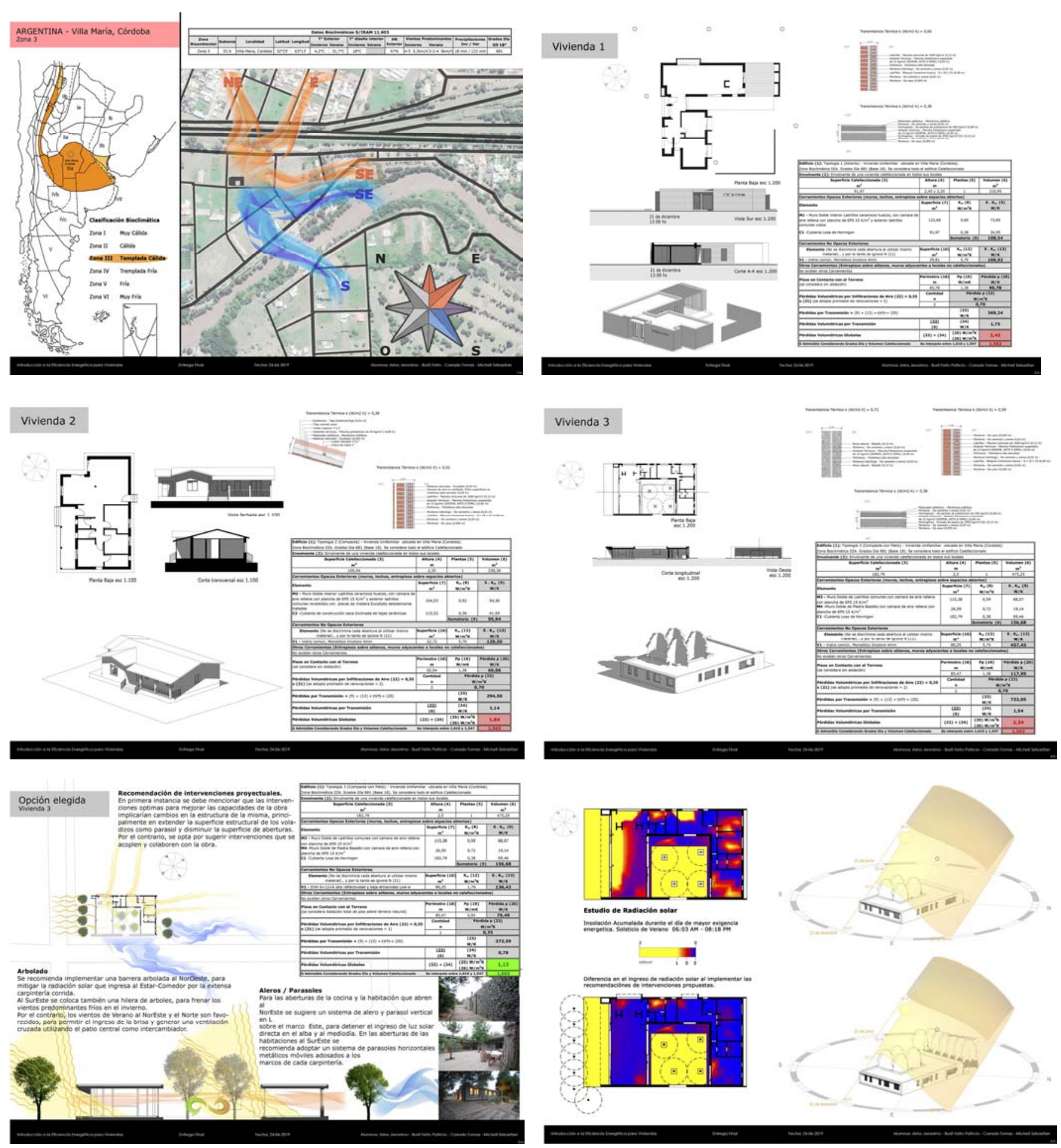

Figure 13. Final work. Authors Arino, Busti. Feito, Corrado, Micheli.

\section{References}

[1] Evans, J. M., Schiller, S. (1988). Environmental Design and Solar Architecture Buenos Aires. Argentine: Editions University of Architecture, Design and Urbanism. University of Buenos Aires. 5.

[2] IRAM 11603 standard (2012). Thermal conditioning of

buildings. Bioenvironmental classification of Argentine Republic. Buenos Aires. Argentine.

[3] Panvini, M. J.; Saldi, R. (2019). Table 1 of own elaboration: Recommendations of passive design strategies. Rosario. Argentine.

[4] Panvini, M. J.; Saldi, R. (2019). Table 2 of own elaboration: Effects of climate of different regions in housing shape. Rosario. Argentine. 
[5] Panvini, M. J.; Saldi, R. (2019). Table 3 of own elaboration: Criteria and design recommendations bioclimatic for arrangement of the complex. Rosario. Argentine.

[6] Panvini, M. J.; Saldi, R. (2019). Table 4 of own elaboration: Criteria and design recommendations bioclimatic for house arrangement. Rosario. Argentine.

[7] Bielsa, M. E.; Cortés, A.; Greppi, O.; López, N. (2011). Ordinance 8757. Hygrothermal aspects and energy demand of buildings. Rosario. Argentine.

[8] Fein, M. (2013). Decree 985. Regulatory application of hygrothermal aspects and energy efficiency of constructions. Rosario. Argentine.

[9] Javkin, P. (2020). Decree 816. Regulatory application of hygrothermal aspects and energy efficiency of constructions. Rosario. Argentina.

[10] Municipality of Rosario (2013). Solar Exposure Factor SEF Values Worksheet. Rosario. Argentine.

[11] IRAM 11601 standard (1996). Thermal conditioning of buildings. Calculation method. Thermal properties of components and building elements in steady state. Buenos Aires. Argentine.

[12] IRAM 11605 standard (1996). Thermal conditioning of buildings. Living conditions in homes. Maximum values of thermal transmittance in opaque closings. Buenos Aires. Argentine.

[13] IRAM 11625 standard (2000). Verification of the risk of water vapor condensation. Buenos Aires. Argentine.

[14] IRAM 11630 standard (2000). Thermal insulation of buildings. Verification of its hydrotermic conditions. Verification of the risk of surface and interstitial water vapor condensation in singular points of exterior walls, floors and ceilings of buildings in general. Buenos Aires. Argentine.

[15] IRAM 11604 standard (2001). Thermal insulation of buildings. Verification of its hydrotermic conditions. Energy saving in heating. Volumetric coefficient $G$ of heat losses. Calculation and limit values. Buenos Aires. Argentine.

[16] IRAM 11900 standard (2010). Building heating energy efficiency label. Buenos Aires. Argentine. 